\title{
Design of a Dual Band Rectangular Microstrip Antenna
}

\author{
Ranjan Mishra*, Raj Gaurav Mishra \\ Department of Electronics, Instrumentation \& Control Engineering \\ University of Petroleum \& Energy Studies \\ Dehradun-248007, Uttarakhand, India \\ *Corresponding author: rmishra@ddn.upes.ac.in \\ R. K. Chaurasia \\ Department of Electronics \& Communication Engineering \\ Faculty of Engineering \& Technology \\ The ICFAI University, Jaipur, India
}

(Received August 31, 2017; Accepted September 13, 2017)

\begin{abstract}
The objective of the paper is to design and investigate a rectangular microstrip antenna that covers the band from 2.4 to 3.6 GHz. The proposition consolidates investigation of fundamentals of microstrip patch antenna. A progression of simulation in Ansoft HFSS (High Frequency System Simulation) has been carried out to discover the dual operating frequency. The qualities of the patch antenna rely on its different geometrical parameters. The investigation is carried in terms of two prime factors: Return loss and radiation pattern.
\end{abstract}

Keywords- Microstrip antenna, Dual band, Return loss, Bandwidth

\section{Introduction}

A microstrip antenna is of low profile and low weight (Garg et al., 2001). It is basically a narrowband antenna that can be made effectively on the printed circuit board. Here a metallic layer in a specific shape is reinforced on a dielectric substrate, which frames a transmitting component and another persistent metallic layer on the opposite side of as ground plane (Mishra, 2016). Any persistent shape can be utilized as the transmitting patch. Microstrip antennas are mechanically rough and can be effortlessly mounted on any surfaces. The span of the microstrip antenna is identified with the operating frequency. The utilizations of microstrip antennas are more over the microwave frequency (Coulibaly et al., 2008) because of their geometry and sharp resonance. At frequencies lower than a microwave, microstrip antenna fails to synchronize well on account of the sizes required. Microwave frequency accounts for the frequency greater than 1 GHz.

A symmetric presentation of the microstrip antenna is shown in Fig. 1. Here two metallic layers and a dielectric layer form the important part of the basic antenna. These three layers are transmitting plane, confined plane and ground plane. Copper makes it very easy and comfortable to design the conducting layers (Mishra et al., 2016). The shape of the microstrip antenna can be square, rectangular, dipole, triangular, curved or some fundamental shapes (Su et al., 2005). For the ease of design and simplicity, rectangular shape is chosen in this paper. The dielectric constant of the confining layers is in between 2.4 and 12.1. In our paper, we choose this value as 4.4 (Mishra et al., 2016). This is the dielectric constant of FR4. This is most easy in availability and also the cheapest one. 
International Journal of Mathematical, Engineering and Management Sciences

Vol. 3, No. 4, 438-443, 2018

https://dx.doi.org/10.33889/IJMEMS.2018.3.4-031

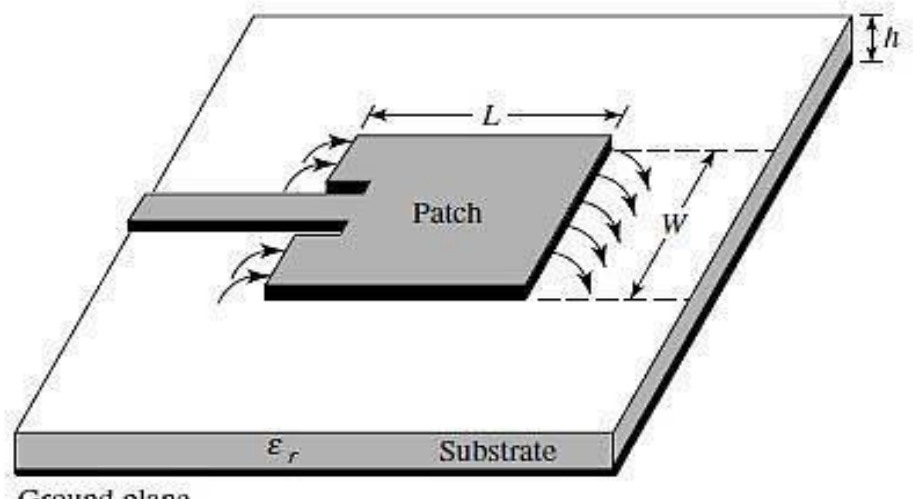

Ground plane

Fig. 1. Microstrip patch antenna

\section{Antenna Dimension and Result}

In a rectangular microstrip antenna its dimension is primary factors for effective radiation. The dimensions are its length and width.

The effective Length (L) and Width (W) of the antenna are given as (Balanis, 2012):

$$
\begin{gathered}
L=c / f_{r}=\frac{C}{2 f_{r} \sqrt{\varepsilon_{r}}} \\
W=\left(\frac{c_{0}}{2 f_{r}}\right)\left(\frac{\varepsilon_{r}+1}{2}\right)^{-1 / 2} .
\end{gathered}
$$

Here, $f_{r}$ is the operating resonant frequency and $\mathcal{E}_{r}$ is the dielectric constant.

At $2.4 \mathrm{GHz}$ (the main resonant frequency), the two dimensional planer representation of the antenna is shown in Fig. 2, whereas the different dimensions are shown in Table 1.

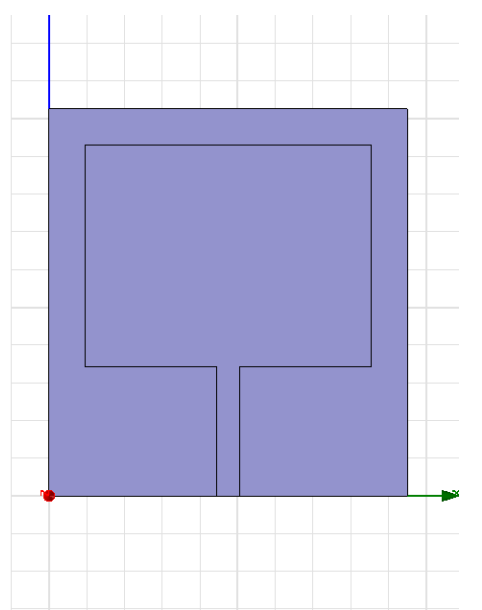

Fig. 2. Simulated structure of antenna 
International Journal of Mathematical, Engineering and Management Sciences

Vol. 3, No. 4, 438-443, 2018

https://dx.doi.org/10.33889/IJMEMS.2018.3.4-031

Table 1. Dimension of rectangular microstrip antenna

\begin{tabular}{|c|c|c|}
\hline S. No. & Parameters & Value (in mm) \\
\hline 1 & Height of substrate & 1.58 \\
\hline 2 & Length of substrate & 51.29 \\
\hline 3 & Width of substrate & 47.49 \\
\hline 4 & Length of ground plane & 51.29 \\
\hline 5 & Width of ground plane & 47.0 \\
\hline 6 & Thickness of ground plane & 0 \\
\hline 7 & Origin of radiation box & $-5,-5,-5$ \\
\hline 8 & Length of radiation box & 61.29 \\
\hline 9 & Width of radiation box & 57.49 \\
\hline 10 & Thickness of radiation box & 11.58 \\
\hline 11 & Origin of port & $22.23,0,0$ \\
\hline 12 & Thickness of port & 1.58 \\
\hline 13 & Width of port & 3.02 \\
\hline 14 & Origin of patch & $4.74,17.12,1.58$ \\
\hline 15 & Length of patch & 29.43 \\
\hline 16 & Width of patch & 38.01 \\
\hline 17 & Position of feed line & $22.23,0,1.58$ \\
\hline 18 & Length of feed line & 17.12 \\
\hline 19 & Width of feed line & 3.02 \\
\hline & & \\
\hline
\end{tabular}

The resonant frequency plot (return loss) is shown in Fig. 3. It is clear from the figure that it is single band antenna. A rectangular structure contained from the set of dimension equation results in a single band.

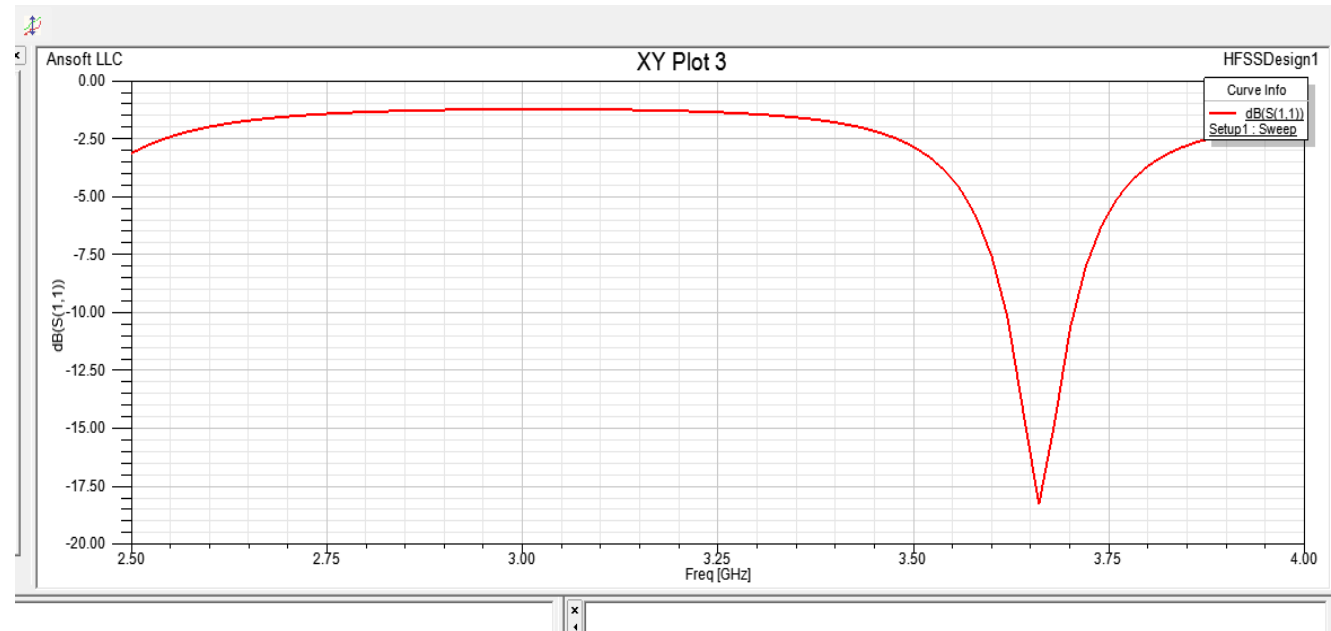

Fig. 3. Return loss of antenna 
International Journal of Mathematical, Engineering and Management Sciences

Vol. 3, No. 4, 438-443, 2018

https://dx.doi.org/10.33889/IJMEMS.2018.3.4-031

In the final step one rectangular cut (slot) is carve don the patch (rectangular front structure). The systematic diagram and dimensions are shown in Fig. 4 and Table 2 respectively.

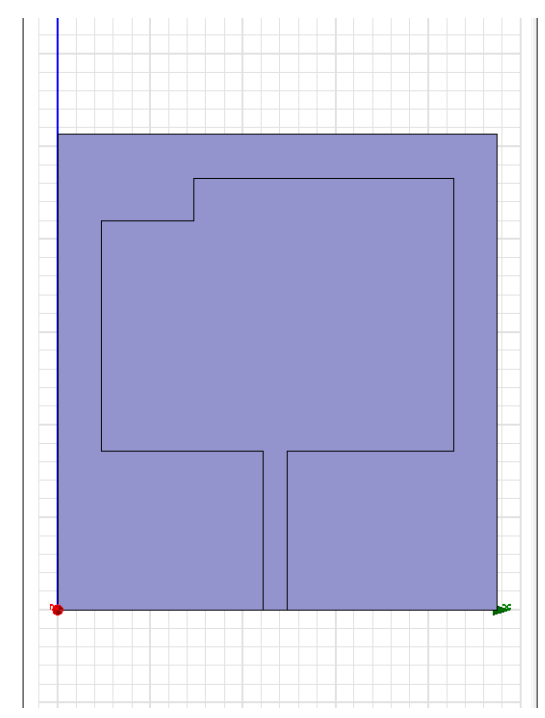

Fig. 4. Antenna (final) with a rectangular slot

Table 2. Dimension of final antenna

\begin{tabular}{|c|c|c|}
\hline S. No. & Parameters & Value (in mm) \\
\hline 1 & Height of substrate & 1.58 \\
\hline 2 & Length of substrate & 51.29 \\
\hline 3 & Width of substrate & 47.49 \\
\hline 4 & Length of ground plane & 51.29 \\
\hline 5 & Width of ground plane & 47.0 \\
\hline 6 & Thickness of ground plane & 0 \\
\hline 7 & Origin of radiation box & $-5,-5,-5$ \\
\hline 8 & Length of radiation box & 61.29 \\
\hline 9 & Width of radiation box & 57.49 \\
\hline 10 & Thickness of radiation box & 11.58 \\
\hline 11 & Origin of port & $22.23,0,0$ \\
\hline 12 & Thickness of port & 1.58 \\
\hline 13 & Width of port & 3.02 \\
\hline 14 & Origin of patch & $4.74,17.12,1.58$ \\
\hline 15 & Length of patch & 29.43 \\
\hline 16 & Width of patch & 38.01 \\
\hline 17 & Position of feed line & $22.23,0,1.58$ \\
\hline 18 & Length of feed line & 17.12 \\
\hline 19 & Width of feed line & 3.02 \\
\hline 20 & Position of slot & $4.74,46.55,1.58$ \\
\hline 21 & Length of slot & -4.55 \\
\hline 22 & Width of slot & 10 \\
\hline & & \\
\hline
\end{tabular}


International Journal of Mathematical, Engineering and Management Sciences

Vol. 3, No. 4, 438-443, 2018

https://dx.doi.org/10.33889/IJMEMS.2018.3.4-031

The rectangular slot creates a capacitive effect and produced one more resonance. Thus the final antenna ha $\mathrm{s} 2$ resonance of frequencies. These two produces the desired dual band.

The return loss plot of the final antenna showing the two bands is shown in Fig. 5.

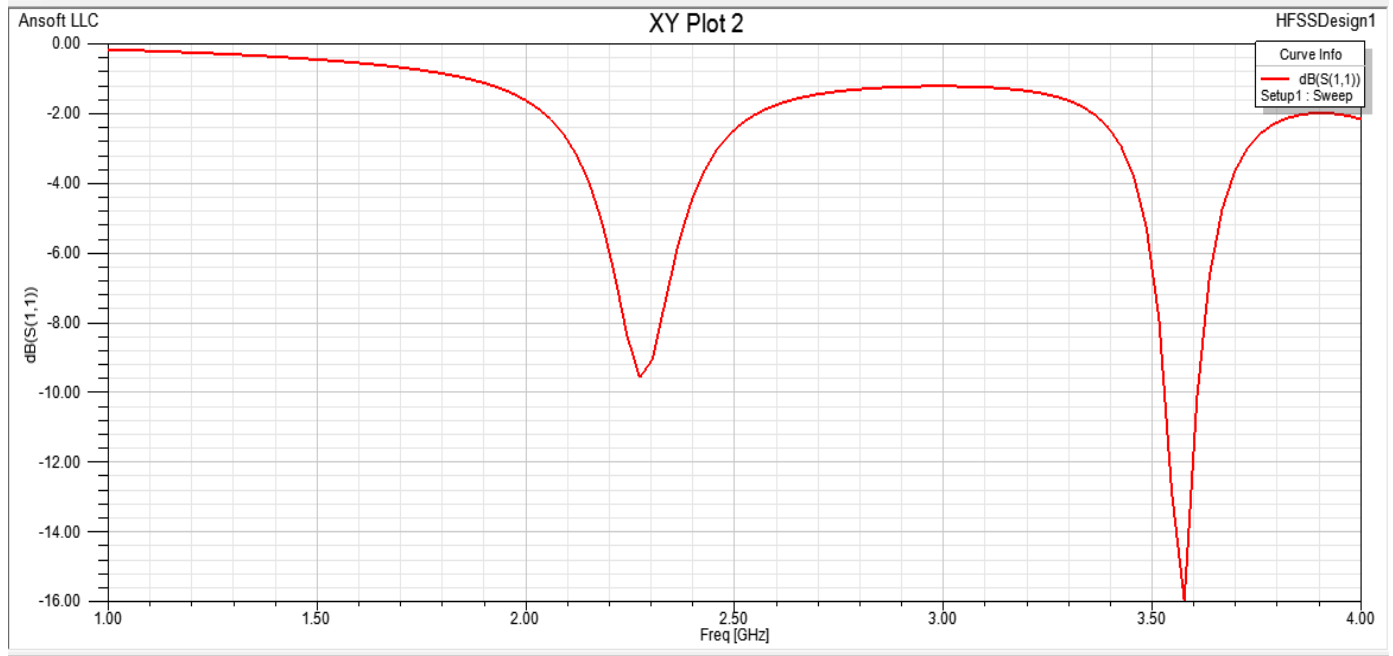

Fig. 5. Return loss of Final Antenna.

The radiation pattern is shown in Fig. 6. It has two lobes resulting from the two bands.

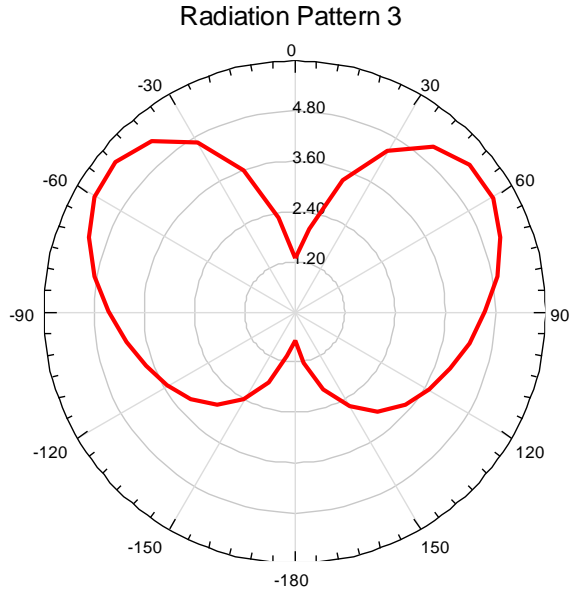

Fig. 6. Radiation pattern of final antenna 
International Journal of Mathematical, Engineering and Management Sciences

Vol. 3, No. 4, 438-443, 2018

https://dx.doi.org/10.33889/IJMEMS.2018.3.4-031

\section{Conclusion}

A rectangular microstrip antenna showing resonance operation at dual band antenna has been designed and presented. The antenna supports a good dual frequency operation in the range 2.4 $\mathrm{GHz}$ and $3.6 \mathrm{GHz}$. the radiation pattern is distinct and directional. The simple rectangular antenna is good operating in Microwave frequency.

\section{Reference}

Balanis, C. A. (2012). Frequency independent antennas antenna miniaturization and fractal antennas. In Antenna Theory: Analysis and Design (pp. 619-623). Wiley-Interscience.

Coulibaly, Y., Denidni, T. A., \& Boutayeb, H. (2008). Broadband microstrip-fed dielectric resonator antenna for X-band applications. IEEE Antennas and Wireless Propagation Letters, 7, 341-345.

Garg, R., Bhartia, P., Bahl, I., \& Ittipiboon, A. (2001). Microstrip antenna design handbook. Artech House.

Mishra, R. (2016). An overview of microstrip antenna. HCTL Open International Journal of Technology Innovations and Research, 21(2) 1-17.

Mishra, R., Jayasinghe, J., Mishra, R. G., \& Kuchhal, P. (2016). Design and performance analysis of a rectangular microstrip line feed ultra-wide band antenna. International Journal of Signal Processing, Image Processing and Pattern Recognition, 9(6), 419-426.

Mishra, R., Mishra, R. G., \& Kuchhal, P. (2016, September). Analytical study on the effect of dimension and position of slot for the designing of ultra wide band (UWB) microstrip antenna. In Advances in Computing, Communications and Informatics (ICACCI), 2016 International Conference on (pp. 488493). IEEE.

Su, S. W., Wong, K. L., \& Tang, C. L. (2005). Band-notched ultra-wideband planar-monopole antenna. Microwave and Optical Technology Letters, 44(3), 217-219. 